\title{
O chapéu de meu pai
}

\section{Conto de Aurélio Buarque de Holanda}

\begin{abstract}
A ARNON DE MELO
A lfvida luz dos ćrios é agora mais triste, à claridade da manhã nascente que vai aos poucos invadindo a sala. Da cadeira onde me acho sentado, na saleta de espera, vejo as mãos de meu Pai cruzadas sobre o peito. O ventre, timpanoso, sobreleva as bordas do caixão. Vem de lá dentro um choro abafado. Alguns dormem, exaustos: ligeira trégua ao sofrimento. Ardem-me os olhos, da noite sem sono e do muito que chorei. Tenho a cabeça reclinada no encosto da poltrona, numa postura de aparente sossego, e chego por momentos a enganar-me, a pensar que estou sereno. $\mathrm{Na}$ janela que daqui avisto, a cortina preta drapeja manso, agitada pelo brando vento do amanhecer. Do porta-chapéus, a um canto da parede, pende um chapéu, como coisa abandonada. É o chapéu de meu Pai. É um pedaço daquele que se encontra ali perto estendido, morto, as largas mãos cruzadas sobre o peito, e o rosto, em vida tão vermelho, agora de uma brancura macilenta. É algưma coisa dele, que a morte não destruiu.

Meus olhos se cravam no chapéu. Está no cabide tal como meu Pai o usava - quebrado para a frente - o chapéu marrom, comum, de abas debruadas, o chapéu de meu Pai. Por menos que deseje pensar nisto, meu Pai começa a emergir, vivo, bulindo, desse chapéu, que era seu. Vendo de lado o chapéu, estou a ver o dono de perfil, o nariz breve e saliente, o rosto sangufneo, um tanto cavado nos últimos tempos, a costeleta curta, uma parte do bigode, ruivo e ralo, de que ele nunca abriu mão.

O chapéu acompanha meu Pai nos seus movimentos, sombreando-lhe um tanto a face. Está no seu verdadeiro lugar, a cabeça de meu Pai. Sim, está. Lá vem o velho chegando para casa, nos fins de tarde, cansado, já doente. Lá vem. É ele: o chapéu marrom, comum, desabado na frente, aquele jeito de andar, meio curvado, lento, da velhice. Chega. Empurra um lado da veneziana, puxa o ferrolho, entra. Põe o chapéu no cabide, ali mesmo onde o vejo agora, bem junto do espelho do móvel. Algumas vezes, olha-se ao espelho, cofia rápido o bigode, e vai entrando. $\mathrm{Na}$ sala de jantar, senta-se e com minha Mãe começa a falar das eternas coisas do dia-a-dia. Mamãe conta dos incidentes domésticos: falta de água, o leite que talhou, aborrecimentos com a empregada, "uma grandessissima respondona". Meu Pai se queixa dos negócios, que vão de mal a pior - "uma crise pavorosa, o comércio, um paradeiro medonho, e o governo é impostos e mais impostos, um fim de mundo". Mamãe é mais calma: - "Ora, homem! Vamos vivendo. Os meninos trabalham, vão ajudando. Já estamos velhos. Paciência." Ele dirá que trabalhou a vida toda, e era para ter uma velhice descansada.

O chapéu fica sozinho, até o dia seguinte, pois geralmente meu Pai não sai de casa à noite de uns tempos para cá. A gente olha o porta-chapéus e adquire a certeza de que o dono da casa não saiu. Não é só porque vê o chapéu: é porque vê a pessoa. Se nos descuidarmos, diremos, apontando o chapéu: - "Olhe Seu Manuel ali."
\end{abstract}

Pela manhã - assim, de dia - o chapéu é posto com o maior cuidado. Meu Pai se mira demoradamente ao espelho. Está bem barbeado. Faz a barba em casa, à navalha - nada de gilete. $\mathrm{O}$ rosto passa. Algum tanto chupado, uns pés-de-galinha perto dos olhos (procura estirar a pele com os dedos), o par de rugas muito fundas descendo-lhe das abas do nariz ao canto dos lábios... Mas passa. O diabo é a falta dos dentes. Breve mandará fazer uma chapa dupla. Tolice: 
não irá andar rindo com as folhas. Demais, a expressão da fisionomia é relativamente boa. Corado, os cabelos em ondas, louros, raros fios brancos, apesar dos seus bons 60 anos, e os olhos azuis, dum azul claro, herdados do avô português. Não é careca: só isto!... E os óculos de aros de ouro são vistosos. - "Manuel!" Responde meio aborrecido: - "Que é?" Estava dando um jeito melhor ao quebrar do chapéu. - "Sim, eu trago, não se incomode, não." Ótimo assim.

Vai saindo. Agora o chapéu anda na mão, um pouco acima da cabeça: - "Bom dia, D. Hortênsia." A vizinha desmancha-se num sorriso. (Mamãe não gosta nada desses sorrisos da vizinha.) De onde em onde o chapéu sai por alguns segundos da cabeça de meu Pai, muito relacionado nesta rua. Por vezes o cumprimento é menos solene - apenas um toque de dedos na aba. $E$ rua fora lá vai o chapéu, integrado em meu Pai - órgão do seu corpo, complemento essencial da sua cabeça, do seu todo.

Chegando à casa comercial, se não encontrar tudo em ordem, é possível que o chapéu venha a perder, por momentos, o ar composto, a dignidade habitual. Talvez meu Pai, zangado, tirando-o, bata com ele no balcão, como quem dá murros. Mas a raiva passará depressa, e meu Pai começará a compor o chapéu, a ajeitá-lo, a reimprimir-lhe a feição própria. Desamassa-o, sulca-o no centro da copa com as pontas dos dedos da mão espalmada, e, com o polegar e o indicador, concava-o lateralmente. Pronto.

Mais tarde, à hora do almoço, como está fechado o comércio, há pouca gente pela rua e meu Pai tem fome, botará o chapéu à vontade e caminhará menos lento que de costume. Entrará em casa suado, nos dias quentes, enxugando o rosto com o lenço: - "Diabo! isto é um calor insuportável. Não há quem agüente..." Tomará seu banho antes de almoçar, e falará, como sempre, da crise pavorosa.

O pãozeiro deixa na porta a mochila, suspensa de um ferrolho. Vão surgindo os primeiros transeuntes - a gente humilde, que principia a trabalhar cedinho, quando os galos ainda cantam, para ganhar a vida e garantir a tranqülidade dos mais felizes. Alguém chora lá dentro, choro convulso: é minha irmã.

Pendente do gancho, ali, abandonadamente inútil, o chapéu me recorda um despojo de guerreiro vencido. Serve-me de ponto de referência para a reconstituição, sem ordem cronológica, de um passado inteiro. $O$ pranto me devolve à realidade do momento, e agora o chapéu me oferece de meu Pai uma imagem muito próxima - a do velho tirando-o quanto entrava na casa de saúde, para nunca mais o usar. Estava pálido, então. O chapéu, acompanhando-o inseparável. O doente torcia-se a gemer; dilaceravam-no dores agudas: e de repente o chapéu saía do lugar e ia para a cabeça de meu Pai, que andava, a passeio ou a negócio, tirando-o para cumprimentar alguém, ao passar diante de uma igreja, ou cortejo fúnebre, ou por outro motivo. $\mathrm{E}$, ao trazer do hospital o chapéu - há coisa de cinco ou seis horas -, parecia-me trazer comigo um pouco (digo mal), uma parte essencial de meu Pai, que ficara no leito de morte, até ser conduzido num carro para casa, onde se acha, ali na sala, no caixão, com o rosto lfvido, o ventre inchado, as mãos em cruz sobre o peito.

As velas ardem. Estão já no fim. A cera escorre em gotas pelo fuste e acumula-se ao pé dos castiçais. À cabeceira do morto, o crucifixo - um Cristo de metal por cuja presença consoladora Seu Sampaio da casa mortuária cobra caro, acrescentando não se tratar de aluguel, que "santo não se vende nem se aluga".

Cristo é filho de Deus, explicava meu Pai, ao falar-me do mistério da Santíssima Trindade, que eu não havia jeito de compreender bem. Meu Pai acreditava em Deus, na religião. Só não ia lá muito com os padres, tanto que, sabendo que morreria, não pediu confessor. $\mathrm{E}$, católico, não participava do horror de alguns aos protestantes - os "freis-bodes", como dizia minha avó -e gostava de, uma vez ou outra, ir às suas sessões de espiritismo. Contudo, esse ecletismo religioso não exclúa uma crença poderosa, entranhada, que não o desamparou nem nos derradeiros momentos: a crença em Deus. Ao fazer um plano, ao sacar sobre o futuro, invariavelmente Deus entrava em cena, como força de que dependesse a concretização daquele desejo: - "Este ano as coisas estiveram muito ruins. Uma crise pavorosa. Mas o ano vindouro, se os negócios melhorarem, com os poderes de Deus, eu..." Se estava de chapéu, tirava-o na certa, erguia-o por um instante, muito respeitoso, ao dizer - "com os poderes de Deus". "Eu tenho fé em Deus", "Deus há de me ajưdar", "Deus é pai" - estas frases não Ihe salam da boca sem lhe sair da cabeça o chapéu.

Volto-me para um retrato dele rapaz. Já muito desbotado, quase não deixa divisar os traços fisionômicos de meu Pai nessa época. Devia ser por volta dos começos da República. Morava ele, então, em Tatuamunha, sua terrinha natal. Falava dos pastoris do seu tempo - bom tempo! -, da graça de algumas pastoras, do encanto das jornadas que cantavam, e das paixões que 


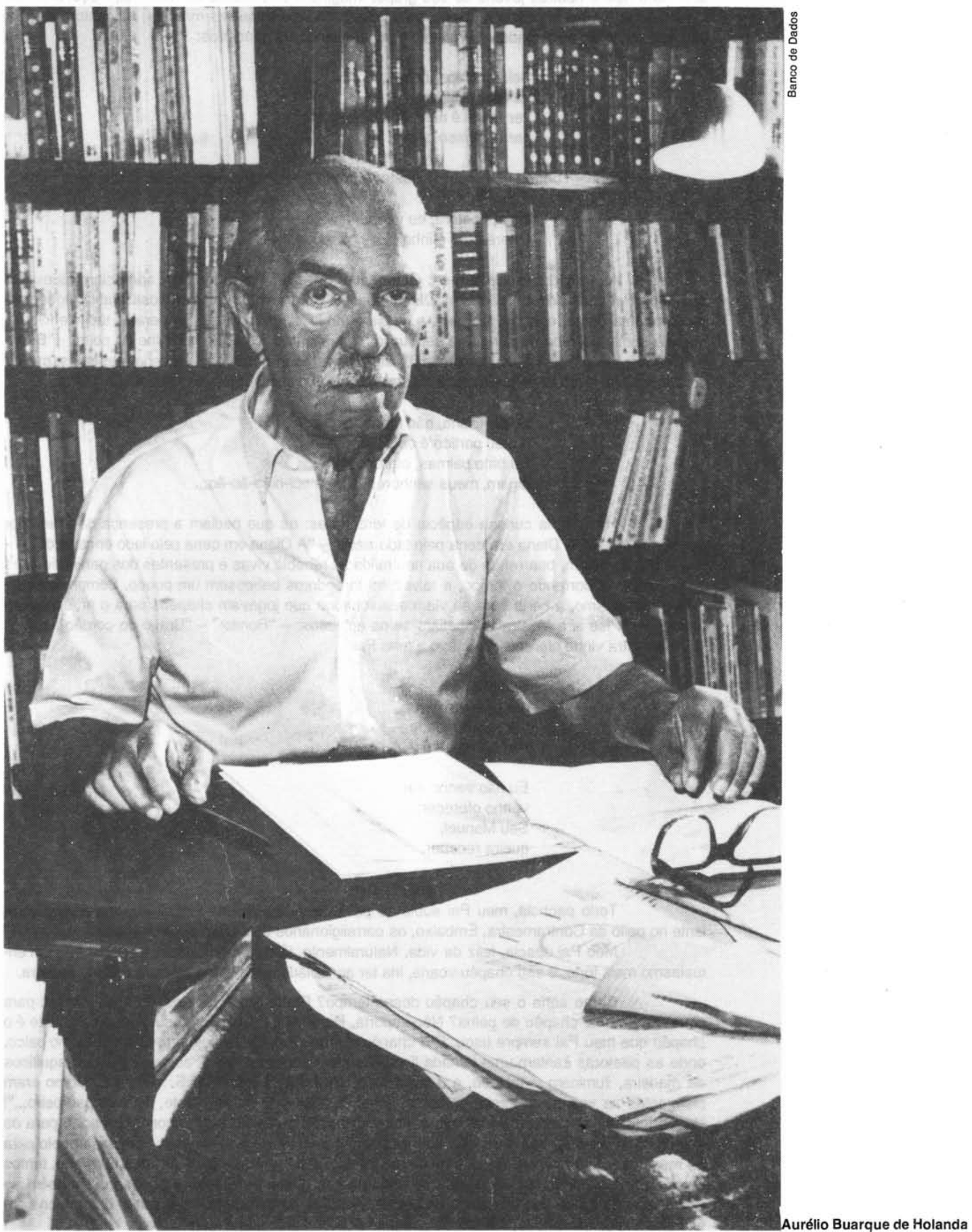


acendiam nele e noutros jovens do seu grupo. Imagino o entusiasmo de meu Pai, moço, ar̉dente, romântico, até meio chegado à poesia, pela beleza de uma daquelas matutas. As pastoras - cordão azul e cordão encarnado - surgiam alegres, agitando os pandeiros:

Belas companheiras, vamos a Belém ver quem é nascido para o nosso bem.

Vinham outros números. O Pastor sempre a arrastar o seu cajado. Chegava o Fúria:

Olha, pastora, eu venho falar-te.

Queres ser minha? Eu posso levar-te.

As jornadas sucediam-se. Começavam a dividir-se os grupos; apareciam os exaltados. Meu Pai seria pelo cordão azul. Discussões. A Contramestra, maravilhosa. Sabia requebrarse com tanta graça, cantava tão bem, e dirigia a meu Pai um olhar tão temperado, tão intencional, que ele sentia bulir-lhe no sangue a sensualidade lusitana, o coração pular-lhe no peito. - "Bravo da Contramestra!" - "A Mestra em cena!" Digladiavam-se os partidos. Haveria presentes, muitos presentes. Um arrebatado chamava a Mestra com todo o cordão. Novas jornadas. A Diana:

Sou a Diana, não tenho partido, o meu partido é os dois cordão.

Eu bato palmas, ofereço flores;

digam, meus senhores, vossa opi-nião-ão-ão...

Havia uma curiosa espécie de torcedores: os que pediam a presença da Diana por um dos lados: - "A Diana em cena pelo lado azu!!" - "A Diana em cena pelo lado encarnado!" Tinha a Diana, assim, boa renda de sua neutralidade: recebia vivas e presentes dos partidários das duas cores. la correndo o tempo, e talvez os torcedores bebessem um pouco. Sempre a subirIhes o entusiasmo, a certa hora se viam apaixonados que jogavam chapéus para o ar, depois ao tablado: - "Pise aí a Mestra!" Repetiam-se os aplausos: - "Bonito!" - "Bravo do cordão azul!" A Contramestra vinha oferecer um cravo a meu Pai:

Seu Manuel, me faça um favor:

por sua bondade receba esta flor.

Eu não venho dar, venho oferecer;

Seu Manuel, queira receber.

Todo pachola, meu Pai subia ao palco, punha a flor na botoeira e uma pelega estalante no peito da Contramestra. Embaixo, os correligionários deliravam em aplausos.

Meu Pai descia, feliz da vida. Naturalmente, lá pela madrugada, à pressão de um entusiasmo mais forte, o seu chapéu voaria, iria ter ao tablado, para que o pisasse a Contramestra.

Como seria o seu chapéu desse tempo? Preto, grave, solene, de abas viradas para cima? Usaria ele chapéu de palha? Não importa. Para mim, o chapéu ali suspenso do cabide é o chapéu que meu Pai sempre usou. É o chapéu de meu Pai. Lá vai pelo ar o chapéu, cai no palco, onde as pastoras cantam uma jornada linda. Candeias de querosene, atadas a postes raquíticos de madeira, iluminam o tablado, e o largo todo, em frente à igreja de S. Gonçalo. (Como eram plangentes as vozes, na igreja, pelas novenas: "S. Gonçalo de Amarante, glorioso padroeiro....! Vozes femininas, quentes de fé, quẹ pediam felicidade ao santo seu patrono: boa sorte para os maridos nas pescas; boa produção dos roçados, que as formigas invadiam; bom casamento para as meninas; a cura da maleita dos meninos; tranqüilidade e fartura para os lares humildes, tantos deles perdidos dentro do coqueiral que ensombrava quase por inteiro o povoado.) Também se vêem, acesos ao pé dos tabuleiros de bolos, brandões de carrapato - sementes de mamona enfiadas em talos compridos. A multidăo comprime-se. Vai animada a festa. 
O leilão tem muitos licitantes. Grita o pregoeiro, alto e pausado, depois de pedir que "batizem" o objeto:

- Mil-réis me dão por uma melancia que deram ao milagroso S. Gonçalo...

Alguém oferece mais:

- Mil e quinhentos.

- Mil e quinhentos me dão...

- Dois mil-réis.

Todos desejam possuir a melancia do santo. Em pouco ela está valendo cinco milréis. Rompem as pilhérias:

- Seis mil-réis para o Silva não ver.

O leiloeiro:

- Seis mil-réis...

- Seis e quinhentos para o Chico não cheirar...

gado:

Até que, já não havendo quem dê mais, o leiloeiro faz a afronta, num português casti-

- Afronta faço que mais não acho; se mais achara, mais tomara. Dou-lhe uma, douIhe duas, dou-lhe três: já entreguei, está entregue.

A chegança, por outro lado, está dando a nota. No topo de um mastro da embarcação, o gajeiro procura ver, cumprindo ordem, se avista "terras de Espanha e areias de Portugal". Canta: na sua voz, fanhosamente arrastada, como na de todo o pessoal da Catarineta, há uma tinta de melancolia.

Indiferente ao leilão, alheio à chegança, meu Pai vibra com o pastoril. Limpará o chapéu, empoeirado, amarrotado, enquanto as pastorinhas maravilham a assistência com as suas jornadas e os partidários suam de exaltação.

Pipocam foguetes nos ares. O chapéu de meu Pai sobe e desce, anda para um e outro lado, defendendo-o das tabocas.

Passaram-se alguns anos. Meu Pai faz serenata - o luar é claro que parece dia perto da casa onde Mamãe veraneia, com os seus, fugindo à vida monótona do engenho. $O$ namoro está pegado. Dias antes ele passou pela porta da amada com uma acácia na lapela (significa "sonhei contigo"), e a moça deu-lhe um sorriso que o deixou tonto. Um tio de Mamãe, apaixonado por ela, faz concorrência a meu Pai. Este pōe na voz toda a atávica saudade lusitana, e canta, pensando na amada, com o chapéu abandonadamente derreado para a nuca:

Ó palidez imácula, vendita, a palidez serena do teu rosto, que me tem sido tanta vez maldita e tem sido na vida o meu desgosto!

A voz é grave até o tem sido, para subir muito na tanta vez, ainda mais no maldita, bem prolongado, e em seguida baixar, depois de uma volta bonita, em que meu Pai dá tudo que tem o coração, tirando, talvez, o sono à namorada.

Qual foi o seu primeiro cuidado ao saltar em Maceió, pouco antes de noivar? Comprar - Dicionário das Folhas, Flores, Frutos e Raízes, para poder dizer ao seu amor, a quem nunca falara, aquilo que os olhos e as mãos não bastavam a exprimir. Imagino o acanhamento do matuto ao entrar na livraria, de chapéu na mão, amassando-lhe a aba, meio sem jeito para pedir o livro, como se estivesse expondo a estranhos a pureza do seu sentimento.

Um dia - o pedido já foi feito - aparecerá no engenho, o Boa Esperança, muito ancho, no seu cavalo castanho, em visita à noiva. Apeia, tira o chapéu, cumprimenta a noiva e a futura sogra, respeitoso. Conversam algum tempo na sala de visitas, grande, paredes cheias de retratos, enquanto Maria Araquã, ex-escrava, acende o belga. Depois, passarão à sala de jantar. Senta-se à mesa comprida, patriarcal, à direita de minha avó, logo junto da cabeceira (que D. Luísa faz questão de ocupar), tendo a amada em frente. Os futuros cunhados, para ele é como se não existissem. Muito cheio de si, os louros cabelos ondeados com uma liberdade ao lado esquerdo, o bigode pedindo-lhe sempre o afago das mãos. Capricha no pegar do talher; come pouco, e, como D. Luísa insiste - "O senhor não está gostando..." -, afirma que tudo é ótimo, mas recusa, com um sorriso civilizado. Após o jantar, minha avó manda retirar a toalha da mesa e meu Pai começa a leitura de um romance de Escrich, de que ele e a futura sogra gostam muito. Volta e meia os seus olhos procuram os olhos da noiva, que a timidez mantém sempre descidos. Lê bem: a voz pausada, com as inflexões características da fala de cada um dos personagens, moldadas segundo as 
circunstâncias em que as palavras são ditas. $O$ diálogo sai animado, vivo: dá gosto ouvir.

No outro dia, pela manhã, despede-se de todos, no alpendre, e sai no seu cavalo, galopando, para voltar-se na curva da estrada e acenar com o chapéu feito lenço.

Como vem altivo, petulante, o chapéu de meu Pai, no dia do casamento! O cavaleiro todo de escuro, as boas botinas Bostock, a camisa branca, de punhos, peito e colarinho duros, lustrosos, o chapéu preto de copa alta e abas viradas... Seria assim mesmo? Com que elegância o tira ao entrar, para os primeiros cumprimentos! Daí a pouco, emocionado, dá para sentir calor, um calor fora do comum, e o chapéu serve-lhe de leque.

O Sol aparece. É mais intenso o movimento na rua. Transeuntes entreparam à porta, olhando o caixão. A empregada entra e, surpreendida e triste, põe-se a chorar. Lá para dentro cuidam do café. Os rumores vão enchendo a casa. Minha Mãe soluça alto. Chama por mim. Ao levantar-me, olho para o corpo hirto, rígido, livido, macerado, as mãos cruzadas sobre o ventre intumescido. Meu Pai veste um fraque antigo, muito antigo - de quando? nem sei. $O$ enterro será às dez horas. As negras cortinas tremulam ao vento, que, agora mais forte, invade a casa, faz dançar, indecisa, a luz agonizante dos círios. Caminhando ao encontro de Mamãe, vejo no porta-chapéus, bem junto do espelho, o chapéu de meu Pai, que, ao sopro do vento, oscila, oscila - abandonado, triste, esquecido -, como se estivesse acenando, chamando por alguém... 